\title{
Inflation Targeting in a St. Louis Model of the 21st Century
}

\author{
Robert G. King and Alexander L. Wolman
}

This article first appeared in the May/June 1996 issue of Review.

Federal Reserve Bank of St. Louis Review, November/December 2013, 95(6), pp. 543-73.

he St. Louis model of the early 1970s, as described by Andersen and Carlson (1972),
was a small-scale monetarist model of economic activity. Its structure was sharply at
variance with the framework of the major, larger scale macroeconometric models used for policy analysis by the Federal Reserve, both at the time of the inception of the St. Louis model and today.

The St. Louis model had four major features:

- It was sufficiently small that one could actually understand how it worked by looking at the model's behavioral equations and by conducting simulations of it.

- It could be used for policy analysis, specifically for studying the effects of monetary and fiscal policy on inflation, output, and interest rates.

- The monetarist background of its authors meant that the model (1) focused on the quantity of money as the key measure of the stance of monetary policy and (2) contained structural linkages from money to economic activity that are now widely accepted, including the central role of a long-run demand for money that is a relatively stable function of a small number of variables.

- It combined short-run non-neutrality of changes in money with long-run neutrality, in line with the perspective of Friedman and Schwartz (1963a and b).

At the time this article was written, Robert G. King was A. W. Robertson professor of economics at the University of Virginia. Alexander L. Wolman was with the Federal Reserve Bank of Richmond. The authors had thanked Marianne Baxter, Michael Dotsey, Marvin Goodfriend, and Peter Ireland for useful discussions during the preparation of this article and received valuable comments during various presentations of it, particularly from Ben Bernanke, Michael Kiley, Preston McAfee, Edward Prescott, Julio Rotemberg, Christopher Sims, Mark Watson, and Michael Woodford.

This article has been reformatted since its original publication in Review: King, Robert G. and Wolman, Alexander L. "Inflation Targeting in a St. Louis Model of the 21st Century."Federal Reserve Bank of St. Louis Review, May/June 1996, 78(3), pp. 83-107; http://research.stlouisfed.org/publications/review/96/05/9605rk.pdf.

( ) 2013, The Federal Reserve Bank of St. Louis. The views expressed in this article are those of the author(s) and do not necessarily reflect the views of the Federal Reserve System, the Board of Governors, or the regional Federal Reserve Banks. Articles may be reprinted, reproduced, published, distributed, displayed, and transmitted in their entirety if copyright notice, author name(s), and full citation are included. Abstracts, synopses, and other derivative works may be made only with prior written permission of the Federal Reserve Bank of St. Louis. 


\section{King and Wolman}

With Lucas's (1976) critique of policy evaluation, the St. Louis model was largely abandoned by monetarists. The model fell victim to the critique in a particularly rapid and complete manner because its builders had stressed that it contained quantitatively important effects of expectations. 1

In this article, we construct a small-scale modern macroeconomic model that can be used to study the effects of alternative monetary and fiscal policies in a manner consistent with Lucas's recommendations. That is, we build a rational expectations macroeconomic model in which the intertemporal optimization problems of households and firms are explicitly described. We call this a St. Louis model of the 21st century because we believe it is the type of small-scale macroeconomic model that will be systematically employed for the purpose of policy analysis by central banks in the coming years. The model is monetarist in five specific ways that it shares with the St. Louis model:

- Our model contains a stable demand for money that is invariant to alternative monetary policies.

- It incorporates short-run non-neutrality of money with long-run neutrality.

- Frictions in the price-setting process yield a short-run non-neutrality of money that is quantitatively and economically important.

- Once one takes into account anticipated price change, these frictions lead to no quantitatively important long-run trade-off between inflation and real activity.

- Our model places a central emphasis on expectations in consumption choices, investment decisions, asset valuation, and price determination in the tradition of Irving Fisher and Milton Friedman.

We use this model to study an important question in monetary economics that is currently policy-relevant at central banks around the world: What are the consequences of adopting an inflation-targeting rule for monetary policy? We provide detailed information on two versions of this question. First, since most central banks seek to target rates of inflation that are low by the historical standards of their countries, we ask, What are the benefits (or costs) of having a low rate of inflation? Second, since critics of inflation targets are frequently concerned that these may interfere with stabilization policy, we ask, In a setting with sticky prices and demanddetermined output, how do the responses of the economy to various shocks differ from those which would occur if prices were flexible?

Our model's answers to these questions are very monetarist. First, there are major benefits to setting low rates of inflation. That is, Friedman's prescription for long-run monetary policy (setting the nominal interest rate to zero) approximately holds in the long run of our model economy even though we have some imperfect market "frictions" of the form stressed by Tobin (1972a and b). Even if one does not go all the way to a zero nominal interest rate, there are quantitatively important long-run welfare gains from moving from an inflation rate of 5 percent to price stability ( 0 percent inflation). Second, under a regime of perfect inflation targeting (in which the path of the price level is specified exactly by the monetary authority), we find that the responses of our sticky price model are essentially identical to those of a flexible price economy.

Our analysis thus suggests that there are major benefits to implementing an inflation-targeting regime with a low target rate of inflation. To further explore issues that arise in the implementa- 
tion of this regime, we consider (1) the dynamic behavior of the economy if a target path for the price level is implemented with an interest rate rule and (2) the dynamic behavior of real activity if a credible, low inflation path is implemented immediately. We find that it is indeed feasible to implement a policy of targeting the path of the price level with an interest rate rule. We also find that there is zero cost of immediately introducing a credible low inflation program.

\section{THE ST. LOUIS MODEL CIRCA 1972}

The St. Louis model of macroeconomic activity was a small macroeconometric model containing five structural equations, as spelled out in Andersen and Carlson (1972): a total spending equation, a price equation, a long-term interest rate equation, a definition of anticipated price changes based on the long-term interest rate equation, and an Okun's law (1962) link between an output gap and unemployment. In addition, in the background, there were methods of measuring the trend level of real economic activity and the normal level of unemployment.

\section{Money Demand and Expenditure}

The centerpiece of the St. Louis model was a total spending equation, put forward in Andersen and Jordan (1968), that linked the change in nominal gross national product to fourquarter distributed lags of changes in the nominal money stock and of high-employment federal government expenditures. Given that the effects of high-employment expenditures were small, this specification was widely viewed as resulting from a monetarist specification of the demand for money-one with an income elasticity of unity and an interest rate elasticity of zero.

In the macroeconometric model, this specification was the econometric embodiment of the Friedman and Schwartz (1963a and b) method of taking nominal income as proximately exogenous. It could be employed to discuss the effect of monetary changes on nominal income, as in Andersen and Jordan (1968), without discussing the division of nominal income into price level and real output.

\section{Price Adjustment}

As elaborated in Andersen and Carlson (1972), the St. Louis model employed a price equation to describe the division of nominal income into prices and output. That specification related the change in the price level to two factors. First, anticipated changes in prices entered with a coefficient of 0.86 , so that the price equation was taken to be importantly influenced by the beliefs of price setters. Second, a four-quarter distributed lag of changes in nominal income was included as a measure of demand pressure in the macroeconomy.

The builders of the St. Louis model contrasted their approach with the approach used to construct traditional price equations, such as those presented by Eckstein and Fromm (1968). Those who built the St. Louis model emphasized that their tractable specification included important expectations effects and permitted the simultaneous determination of prices and output. This latter feature was sufficiently novel, relative to the standard econometric practice of relating price changes to real demand pressure measures, that it warranted extensive discussion by Tobin 


\section{King and Wolman}

(1972a and b) in his summary of the conference that led to the Eckstein (1972) volume. Since the coefficients on the nominal demand variables summed to 0.10 , the model also implied a Phillips curve-defined by Andersen and Carlson (1972) to be the joint time paths of unemployment and inflation arising from their model, which involved only a very small effect of sustained inflation on real activity. This small trade-off is contrasted with other contemporary studies such as de Menil and Enzler (1972), Klein (1972), Bodkin (1972), and Eckstein and Wyss (1972).

\section{Expectations}

An unusual feature of the St. Louis model was its modeling of expectations. Andersen and Carlson (1972) stressed that expected prices played a key role in the model and that their explicit specification of an expectations mechanism allowed them to explore the trade-off between inflation and unemployment at various horizons. They used the long-term interest rate as an important empirical indicator of expected inflation and, for this reason, also included a structural equation determining the long-term interest rate. The details of their expectations scheme were sharply criticized by Gordon (1972) on theoretical and empirical grounds, although many practical macroeconomists now routinely use the long-term nominal interest rate as a guide to longterm inflation expectations.

\section{A ST. LOUIS MODEL OF THE 21ST CENTURY}

Many of the structural equations of our model economy are obtained by studying the optimization problems of households and firms. In addition, the structural equations include resource constraints and the policy rule of the central bank.

\section{Monetary Services and the Demand for Money}

In our model economy, there is a well-defined demand for money that one can determine from a problem of cost minimization. That is, one can define a demand for money conditional on a pattern of expenditure determined as part of a more general utility maximization problem.

The demand for money stems from a transactions technology—a "shopping time technology" in the terminology of McCallum and Goodfriend (1987) — which governs the amount of time that must be spent to undertake real consumption activity within the period $t$ of our discrete time setup. This shopping time function specifies that time devoted to transactions activity depends negatively on the ratio of the amount of real money balances $\left(m_{t}\right)$ to the amount of real consumption expenditure $\left(c_{t}\right)$ :

$$
h_{t}=h\left(\frac{m_{t}}{c_{t}}\right) .
$$

Throughout, we use notation in which lowercase letters refer to real variables and uppercase letters refer to nominal variables so that $m_{t}$ is the quantity of real balances and is equal to $M_{t} / P_{t}$, where $M_{t}$ is the stock of money held during the period and $P_{t}$ is the price level. 
The opportunity cost of a unit of time spent shopping is given by the real wage rate. The opportunity cost of choosing to hold a unit of money during period $t$ is the discounted value of interest forgone next period, so that the rental price of a unit of cash balances is

$$
\frac{R_{t}}{1+R_{t}} \cdot \underline{2}
$$

Minimizing the flow real cost

$$
w_{t} h_{t}+\frac{R_{t}}{1+R_{t}} m_{t}
$$

through selection of the quantity of real balances accordingly requires that

$$
-w_{t} D h\left(\frac{m_{t}}{c_{t}}\right)\left(\frac{1}{c_{t}}\right)=\frac{R_{t}}{1+R_{t}},
$$

which implicitly defines the demand for money. In this expression,

$$
-D h\left(\frac{m_{t}}{c_{t}}\right),
$$

is the marginal time saving that arises from holding an additional unit of cash balances per unit of consumption expenditure. (We use $D h$ to denote the derivative of the $h$ function with respect to the ratio $\mathrm{m} / \mathrm{c}$, viewing it as a function of this single variable.) In our theoretical analysis, we assume that this time saving is diminishing in the ratio $(\mathrm{m} / \mathrm{c})$. Our empirical work justifies this assumption.

Notice that if the real wage and real consumption grow at the same rate and the nominal interest rate is constant over time, then our specification implies that there is constant "consumption velocity." That is, there is no trend in the ratio $\mathrm{m} / \mathrm{c}$. In our empirical analysis below, we specify that the function

$$
D h\left(\frac{m_{t}}{c_{t}}\right)
$$

takes a specific parametric form

$$
D h\left(\frac{m_{t}}{c_{t}}\right)=\kappa-\left[\left(\frac{m_{t}}{c_{t}}\right) / \zeta\right]^{-\frac{1}{v}},
$$

which then implies that

$$
\left(\frac{m_{t}}{c_{t}}\right)=\zeta\left[\kappa+\frac{R_{t}}{1+R_{t}}\left(\frac{c_{t}}{w_{t}}\right)\right]^{-v} .
$$

This functional form for real money demand per unit of expenditure is close to the constant elasticity structure that is frequently studied in the literature. Notably, if $\kappa=0$, then there is a loglinear money demand function, 


$$
\log \left(m_{t}\right)=\log (\zeta)+(1-v) \log \left(c_{t}\right)-v \log \frac{R_{t}}{1+R_{t}}+v \log \left(w_{t}\right)
$$

More generally, the parameter $\kappa$ allows there to be a finite "satiation" level of real cash balances, $m=\zeta[\kappa]^{-v} c$, which occurs as a limiting case when the nominal interest rate is zero. We choose this parametric form for the $\mathrm{Dh}\left(m_{t} / c_{t}\right)$ function because we want to generate a demand for money that is relatively conventional, while leaving open the issue of whether there is a finite satiation level of cash balances.

\section{Consumption Demand and Labor Supply}

Intertemporal utility maximization leads to demand for consumption $\left(c_{t}\right)$ and supply of labor $\left(n_{t}\right)$, given the allocation of time to shopping $\left(h_{t}\right)$ discussed above. Expected date $t$ lifetime utility is given by

$$
E_{t} U_{t}=E_{t} \sum_{j=0}^{\infty} \beta^{j} u\left(c_{t+j}, l_{t+j}\right)
$$

where the momentary utility function implies that both consumption and leisure $\left(l_{t}\right)$ are goods. Later in the analysis we adopt a parametric specification of this function that has been much used in the real business cycle literature.

Individuals choose contingency plans for consumption, labor supply, real balances, shopping time, and leisure to maximize expected utility subject to a present value budget constraint that links income and expenditure,

$$
E_{t} \sum_{j=0}^{\infty} \Delta_{t, j} P_{t+j} c_{t+j} \leq E_{t} \sum_{j=0}^{\infty} \Delta_{t, j} P_{t+j} \times\left[w_{t+j}=n_{t+j}-\frac{R_{t+j}}{1+R_{t+j}} m_{t+j}\right]+\text { other wealth, }
$$

as well as a time constraint that restricts work, shopping time, and leisure,

$$
n_{t+j}+l_{t+j}+h_{t+j}=1
$$

In addition, as discussed above, there is a technology linking shopping time to current expenditure, $c_{t}$ and real cash balances, $m_{t}$. Since these specifications are standard, we will review them relatively briefly. First, in the present value budget constraint, we are discounting nominal cash flows at date $t+j$ by the discount factor $\Delta_{t, j} \cdot-\frac{3}{}$ Second, also in this expression, we have real prices of work and cash balance holding: $w_{t}$ is the real wage $\left(W_{t} / P_{t}\right.$ where $W_{t}$ is the nominal wage) and the rental price of a unit of real cash is $R_{t} /\left(1+R_{t}\right)$, as discussed above. Third, the time constraint includes time spent "shopping," as well as at working and at leisure: Market work is a residual given determination of leisure demand from utility maximization and time spent shopping from cost minimization.

Maximization of utility subject to these constraints leads to the following efficiency conditions for consumption, leisure, and money balances. These efficiency conditions are structural equations of our small-scale macroeconomic model. Since they contain expectations, they must 
be evaluated as part of a complete rational expectations solution, but presentation of them provides us with the opportunity to describe the main implications that they have, taking expectations as exogenous. First, the efficient selection of consumption requires

$$
E_{t} \beta^{j} D_{1} u\left(c_{t+j}, l_{t+j}\right)=\Lambda_{t} E_{t} \Delta_{t, j} P_{t+j}\left[1-w_{t+j} D h\left(\frac{m_{t+j}}{c_{t+j}}\right)\left(\frac{m_{t+j}}{c_{t+j}^{2}}\right)\right],
$$

for $j=0,1, \ldots$ Second, the efficient selection of labor requires

$$
E_{t} \beta^{j} D_{2} u\left(c_{t+j}, l_{t+j}\right)=\Lambda_{t} E_{t} \Delta_{t, j}\left[P_{t+j} w_{t+j}\right] \text {, }
$$

for $j=0,1, \ldots$ Third, the efficient pattern for cash balance holdings requires that

$$
-w_{t+j} D h\left(\frac{m_{t+j}}{c_{t+j}}\right)\left(\frac{1}{c_{t+j}}\right)=\frac{R_{t+j}}{1+R_{t+j}},
$$

for $j=0,1, \ldots$ In these expressions $\Lambda_{t}$ is the Lagrange multiplier on the wealth constraint and thus represents the lifetime utility gain from an additional dollar of wealth at $t$. We use the notation $D_{i} u$ to denote the partial derivative of the utility function with respect to its $i$ th argument.

In the first of these efficiency conditions, notice that the shopping time technology means that the Beckerian "full price" of a unit of consumption at date $t+j$ involves a time cost of shopping,

$$
\Delta_{t, j} P_{t+j}\left[-w_{t+j} D \dot{h}\left(\frac{m_{t+j}}{c_{t+j}}\right)\left(\frac{m_{t+j}}{c_{t+j}^{2}}\right)\right],
$$

as well as the standard market cost component $\Delta_{t, j} P_{t+j}$. In the second, notice that there is the standard equating of the costs and benefits of forgoing a unit of leisure and supplying it to the marketplace. Together with the lifetime budget constraint, these two equations implicitly determine consumption and leisure demand at all dates in line with a "permanent income" approach to these two actions. The third condition is the "money demand" cost minimization condition discussed above.

\section{Labor Demand, Investment, and Marginal Cost}

As in Rotemberg (1987) and Blanchard and Kiyotaki (1987), we assume that firms have some market power, behaving as monopolistic competitors. (We contrast this to a perfect competition situation in some places below.) In this subsection, we focus on the structural equations arising from the representative firm's decision problem that concern production, labor, and investment demand. In the next subsection, we focus on pricing implications. It is accordingly useful to think about breaking the firm into three separate parts for planning purposes.

First, the production unit takes as given the output level of the firm and the rental price of capital (a transfer price from the investment unit): It determines labor demand and capital demand so as to minimize cost. Second, the investment unit takes as given the market prices of investment goods and the rental price of capital: It determines investment so as to maximize the 


\section{King and Wolman}

value of the firm. The activities of these two units are explored in this section. Third, the pricing unit determines the price of the firm's output, taking into account demand conditions and costs. Throughout, the firm is taken to maximize the expected present value of its profits,

$$
E_{t} V_{t}=E_{t} \sum_{j=0}^{\infty} \Delta_{t, j}\left[P_{t+j} y_{t+j}-W_{t+j} n_{t+j}-P_{t+j} i_{t+j}\right]
$$

subject to the production technology for its final product,

$$
y_{t+j}=a_{t+j} f\left(n_{t+j}, k_{t+j}\right) \text {, }
$$

and the evolution equation for its capital,

$$
k_{t+j+1}-k_{t+j}=\phi\left(i_{t+j} / k_{t+j}\right) k_{t+j}-\delta k_{t+j}
$$

where $\phi(i / k)$ is a positive, increasing and concave function that embodies costs of adjustment for the capital stock.

To describe decisions of the production unit, we employ standard microeconomic conditions for cost minimization. For this purpose, we assume that the output level is given at any arbitrary level $\hat{y}_{t+j}$ and that capital can be rented at price $Z_{t}$. Then, the static conditions for cost minimization are:

$$
\Psi_{t+j} a_{t+j} D_{1} f\left(n_{t+j}, k_{t+j}\right)=W_{t+j}
$$

and

$$
\Psi_{t+j} a_{t+j} D_{2} f\left(n_{t+j}, k_{t+j}\right)=Z_{t+j}
$$

where $\Psi_{t+j}$ is the Lagrange multiplier on the constraint $y_{t+j}=\hat{y}_{t+j}$ and $\Psi_{t+j}$ accordingly is interpretable as nominal marginal cost. The conventional solution to this problem implies that marginal cost is a function of the level of output; the productivity shifter, $a_{t+j}$; and the factor prices, $W_{t+j}$ and $Z_{t+j}$. It also depends on the form of the production function: We assume that the production function (equation 7 ) is constant returns-to-scale, so that marginal cost is independent of output and thus write $\Psi_{t+j}=\Psi\left(a_{t+j}, W_{t+j}, Z_{t+j}\right)$.

In terms of the decisions of the investment unit, we assume that the firm chooses the optimal investment pattern to maximize its present discounted value given the rental price $Z_{t+j}$. This leads to a pair of efficiency conditions,

$$
P_{t}=Q_{t} D \phi\left(i_{t} / k_{t}\right)
$$

and

$$
Q_{t}=E_{t}\left\{\Delta_{t, 1} Z_{t+1}+\left[\phi\left(\frac{i_{t+1}}{k_{t+1}}\right)-\frac{i_{t+1}}{k_{t+1}} \times D \phi\left(\frac{i_{t+1}}{k_{t+1}}\right)+1-\delta\right] \Delta_{t, 1} Q_{t+1}\right\} .
$$


In accord with the investment technology that Hayashi (1982) and others have used to rationalize a Tobin's $q$-theory of investment, the first of these specifications indicates that the investment rate $i_{t} / k_{t}$ is determined by the ratio of the (shadow) price of installed capital $\left(Q_{t}\right)$ to the price of replacement capital $\left(P_{t}\right)$, that is, it is a function of the ratio $q=Q / P$. The evolution of $Q_{t}$ over time takes into account the discounted value of rentals accruing in the future period, as well as the effect of capital accumulation on next period's capital stock and adjustment costs. ${ }^{4}$

\section{Price Setting}

The price-setting structure that we employ follows Calvo (1983), in ways that are recommended by Rotemberg (1987) and are similar to the recent work of Yun (1996). Firms are assumed to be able to change their prices only in specific states of nature and must otherwise satisfy all demand at the quoted price. As we will see, this latter requirement-that we treat as one of the institutions of the marketplace-has important consequences for optimal price setting.

The price-adjustment event occurs with probability $1-\eta$ so that with probability $\eta$ the firm is stuck with a predetermined nominal price. Accordingly, the expected time of price fixity is

$$
(1-\eta) 1+\eta(1-\eta) 2+\ldots+\eta^{n-1}(1-\eta) \eta+\ldots
$$

which is equal to $(1-\eta)^{-1}$. We assume that the average firm adjusts its price every four quarters (once per year) so that $\eta=0.75$, but we also experiment with higher values. The stochastic pricesetting specification also implies a (stationary) distribution of firms in terms of the time that they last adjusted their price. The fraction of firms that last adjusted price $j$ periods ago, $\theta_{j}$, is given by $\theta_{j}=(1-\eta) \eta^{j}$.

This price-setting specification captures two key features of price setting that have been much emphasized by macroeconomists working on price adjustment: The timing and magnitude of price adjustments vary widely across firms in ways that appear stochastic to an outside observer. However, given that the probability of price adjustment $\eta$ is exogenous in the Calvo setting, the frequency of price adjustment cannot adjust to variations in the state of the economy: It cannot change either with the average rate of inflation or with the stage of the business cycle. $\underline{5}$

We assume that firms are monopolistic competitors and that each faces a date $t$ demand schedule of the form

$$
y_{j, t}^{d}=d_{t}\left(P_{t-j}^{*} / P_{t}\right)^{-\varepsilon} \text {, }
$$

if it last adjusted its price $j$ periods ago and selected the price $P_{t-j}^{*} .{ }^{6}$ In this expression, $d_{t}$ is a demand shifter that depends on the state of the economy and $P_{t}$ is the aggregate price level that evolves according to

$$
P_{t}=\left[\sum_{j=0}^{\infty} \theta_{j}\left(P_{t-j}^{*}\right)^{(1-\varepsilon)}\right]^{\left(\frac{1}{1-\varepsilon}\right)} .
$$

Using the stationary fractions given above, the dynamics of the aggregate price level $P_{t}$ can be reduced to 


$$
P_{t}=\left[(1-\eta)\left(P_{t}^{*}\right)^{(1-\varepsilon)}+\eta\left(P_{t-1}\right)^{(1-\varepsilon)}\right]^{\left(\frac{1}{1-\varepsilon}\right)},
$$

where $\eta\left(P_{t-1}\right)^{(1-\varepsilon)}$ represents the influence of the prices charged by the fraction of firms that do not currently change prices in period $t$ and $(1-\eta)\left(P_{t}^{*}\right)^{(1-\varepsilon)}$ represents the influence of the firms that do change prices in period $t$.

In this time-dependent price-adjustment framework, a firm that is rationally setting its price in period $t$ will choose to equate marginal revenue and marginal cost in a discounted, expected value sense. Dynamic marginal revenue stemming from a change in the price is given by

$$
E_{t} \sum_{j=0}^{\infty} \Delta_{t, j} n^{j}\left[(1-\varepsilon) y_{j, t+j}^{d}\right] .
$$

The form of this expression reflects the fact that the price at $t+j$ will remain at the chosen level $P_{t}^{*}$ with probability $n^{j}$. Similarly, the dynamic marginal cost associated with a price change is

$$
E_{t} \sum_{j=0}^{\infty} \Delta_{t, j} \eta^{j}\left[(-\varepsilon) \Psi_{t+j}\left(P_{t}^{*}\right)^{-1} y_{j, t+j}^{d}\right]
$$

We can simplify these expressions as in the standard static case and then equate dynamic marginal cost and revenue to obtain a price that it is optimal to charge:

$$
P_{t}^{*}=\frac{\varepsilon}{\varepsilon-1} \frac{E_{t} \sum_{j=0}^{\infty} \Delta_{t, j} \eta^{j} \Psi_{t+j} d_{t+j} P_{t+j}}{E_{t} \sum_{j=0}^{\infty} \Delta_{t, j} \eta^{j} d_{t+j} P_{t+j}^{\varepsilon} .} .
$$

Three implications of this expression are worth elucidating. First, if marginal cost were constant over time at the level $\Psi$, then we obtain

$$
P^{*}=\frac{\varepsilon}{\varepsilon-1} \Psi
$$

so that the ratio

$$
\mu=\frac{\varepsilon}{\varepsilon-1},
$$

is interpretable as the markup just as in the static case. Second, in the dynamic setting, price setting is influenced by the scale of output (demand) unless the entire sequence of outputs in the numerator and denominator expressions are scaled by a common factor. Third, optimal price setting in the Calvo environment involves forecasting both demand and costs.

Taking the price-setting rule (equation 16) and the price index (equation 15) together, it is clear that there is long-run homogeneity of nominal prices in terms of nominal costs:

$$
P=P^{*}=\frac{\varepsilon}{\varepsilon-1} \Psi=\frac{\varepsilon}{\varepsilon-1} \frac{W}{a D_{1} f(n, k)} .
$$


Accordingly, as all of the other behavioral equations of our model are written in real terms, it follows that our model will display long-run neutrality of money: Permanent changes in the quantity of $M$ will ultimately affect prices and not output, even with short-run rigidity of prices. However, there will be a departure from superneutrality, in that the same frictions that lead to (1) the demand for money and (2) the short-run rigidity of prices will mean that there will be real effects of sustained inflation. In the next section we quantify these real effects.

\section{The Marginal and Average Markup}

Given that firms are charging different prices in our setting, it is clear that there will be different values of markups across firms. We define the marginal markup as that earned by firms which are currently adjusting price, that is,

$$
\mu_{t}^{*}=P_{t}^{*} / \Psi_{t}
$$

We define the average markup as the ratio of the aggregate price level to marginal cost, that is,

$$
\underline{\mu_{t}}=P_{t} / \Psi_{t}
$$

In a steady state with zero inflation, both of these constructions are equal to the static markup

$$
\mu=\frac{\varepsilon}{\varepsilon-1}
$$

but in steady states with inflation or deflation, there will no longer be this equality. Similarly, in response to business fluctuations, the fact that part of the price level is predetermined will lead to different time-series variation in the marginal and average markup.

\section{OPTIMAL INFLATION POLICY IN THE LONG RUN}

A natural method for determining the target rate of inflation is to choose that rate of inflation which maximizes the welfare of the representative household. In this section we conduct such an analysis for the "long run," defined as a steady-state situation in which all variables grow at constant rates in ways that are consistent with the model economy outlined in the previous section. We solve the equations of the model for the link between inflation and welfare, isolating the factors that are important for determining the long-run optimal inflation policy.

In models with perfect competition and continuously adjusted prices, there is a presumption that the optimal inflation policy is that which makes the private cost of holding money equal to the social cost of production, that is, a nominal interest rate of zero. Given a positive real interest rate, this condition represents a prescription for long-run deflation policy that was first made by Milton Friedman (1969). Friedman's conclusion has been replicated in a wide range of theoretical environments.

In particular, letting the rate of inflation be $\pi$ and the level of the real interest rate be $r$, it follows that the definition $(1+R)=(1+r)(1+\pi)$ and the Friedman rule condition $R=0$ together imply that the optimal rate of inflation should be 


\section{Figure 1}

\section{Time Cost of Inflation}

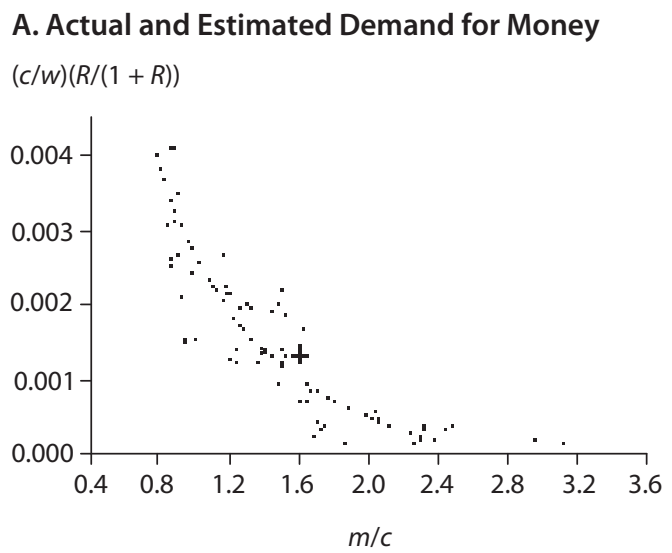

\section{B. Time Saved}

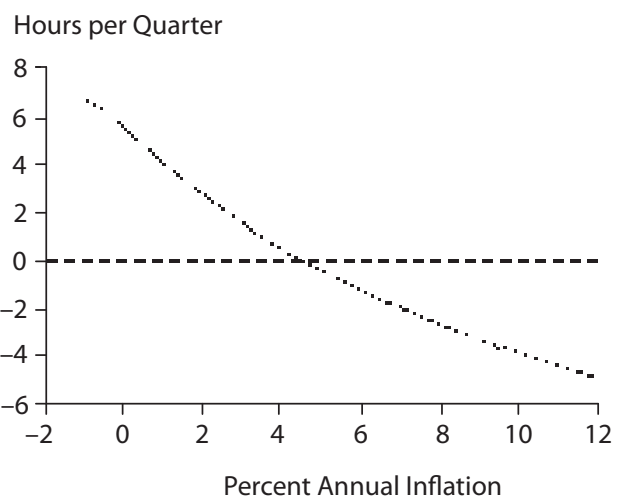

$$
\pi^{f}=-\frac{r}{1+r}
$$

where the superscript indicates that this is the Friedman rule level of the inflation rate. Long-term U.S. data compiled by Ibbotson and Sinquefeld (1982) indicate that the average real return on Treasury bills is between 0 percent and 1 percent so that this represents a recommendation for at most a small deflation.

\section{Estimating the Welfare Gains from Lower Inflation}

One measure of the gains from lower inflation may be computed as the time savings generated as agents increase their cash balances, gains that are sometimes viewed as small. Following the provocative work of Lucas (1993), there has been much recent interest in the magnitudes of these gains. In this article, we use a benchmark estimate from Wolman (1996), the nature of which is displayed in Figure 1.

In the first step, the three-parameter money-demand function (equation 3 ) is fit to annual U.S. time-series data over the 1915-92 period. Each annual observation on the pair of ratios, $\mathrm{m} / \mathrm{c}$ and $(c / w)(R /(1+R))$, enters as a dot in the left panel of Figure $1 .^{-}$The representative individual holds cash balances equal to 1.62 quarters of consumption expenditure at the sample mean (denoted by a " + " in the left panel of Figure 1). The values of $\xi, \kappa$, and $v$ are chosen to provide a best fit in a least squares sense, and the solid line in the left panel traces out the fitted relationship. As it turns out, the estimates indicate a satiation level of real cash balances. Cash balances equal 2.7 quarters of consumption expenditure at the estimated satiation level, which is somewhat smaller than the maximum cash balances in the sample (about 3.3 quarters of consumption expenditure).

In the second step, we compute the time savings that arise as the inflation rate is lowered from a benchmark level of 5 percent per year. For this purpose, we employ the estimated param- 
eter values obtained in the first step and also the sample average value of $c / w$ over 1915-92. That is, given the parameters, the marginal time savings at any level of real balances is

$$
D h\left(\frac{m_{t}}{c_{t}}\right)=\kappa-\left[\left(\frac{m_{t}}{c_{t}}\right) / \zeta\right]^{-\frac{1}{v}} .
$$

Substituting in the formula for the real demand for money from equation 3 and assuming that the real interest rate is invariant to inflation, we can then determine the time savings of moving from one inflation rate to another, which is the integral of such time savings over the relevant range. The right panel of Figure 1 is the result of this computation. We find that a movement from a 5 percent rate of inflation to a 0 percent rate of inflation would lead to a saving of about 5 hours per quarter. Adopting the Friedman rule from an initial position of 5 percent inflation would lead to a saving of about 7 hours per quarter. For an individual working 40 hours per week for 12 weeks in a quarter, these time savings represent about 1 percent of his time. Since the average hours worked by an average work-age individual is lower, about 20 hours per week, it follows that the time saving is roughly 2 percent.

\section{The Markup and Inflation}

In models with monopolistic competition and staggered price setting, economists have long suggested that the Friedman rule is not desirable. One argument that is sometimes made for departing from the Friedman rule is that the markup of price over marginal cost may depend

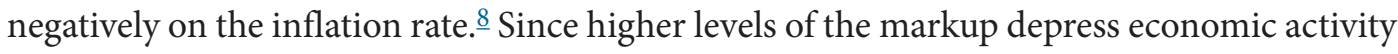
(acting like a tax on factor supplies), the deflation envisioned by Friedman would have social costs, as well as social benefits. Thus, there is an open issue as to the level of the optimal rate of inflation within setups such as ours.

The average markup of price over marginal cost that prevails in our economy depends on two factors,

$$
\underline{\mu}_{t}=\frac{P_{t}}{\psi_{t}}=\left[\frac{P_{t}}{P_{t}^{*}}\right]\left[\frac{P_{t}^{*}}{\psi_{t}}\right] .
$$

These two factors are (1) the marginal markup (defined above as the ratio of price to marginal cost for firms that are free to adjust their prices) and (2) the price adjustment gap (defined as the ratio of the general price level to the price charged by firms that are free to adjust).

The price adjustment gap and inflation. In a steady-state situation, the price adjustment gap is:

$$
\left[\frac{P_{t}}{P_{t}^{*}}\right]=\left[\frac{1-\eta}{1-\eta\left(\frac{1}{1+\pi}\right)^{(1-\varepsilon)}}\right]^{\frac{1}{(1-\varepsilon)}}
$$

This expression is obtained by evaluating equation 15 in a situation where $P_{t}$ and $P_{t}^{*}$ are growing at the rate $\pi$. If there is no inflation, then there is no price adjustment gap in the steady state- 


\section{Figure 2}

\section{Implications of the Price Adjustment Gap}
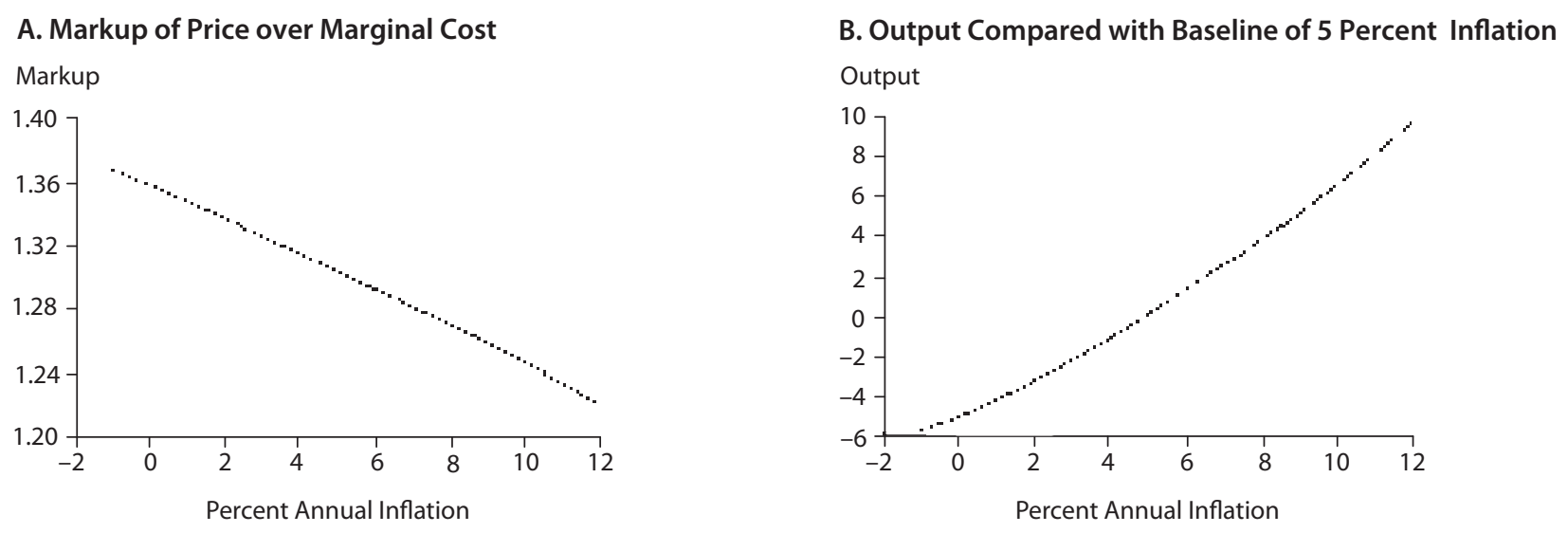

all firms are charging $P^{*}$. At a higher rate of inflation, it follows that $P_{t}$ is less than $P_{t}^{*}$ : A price adjustment gap emerges. This gap reflects the fact that higher inflation mechanically erodes the real value of markups and thus erodes relative prices set by firms in past periods.

We think of this price adjustment gap as a feature of sticky price models that is emphasized by traditional econometric price equations such as those developed in Eckstein and Fromm (1968). The implicit assumption in such studies is that firms set $P_{t}^{*}$ as a fixed markup over marginal cost $\Psi_{t}$. With such an assumption, there is a substantial effect of a sustained inflation on the markup and on macroeconomic activity (displayed in Figure 2). In the left panel, we display the implications of equation 18 for the average markup. To construct this diagram, we assume that there is a gross markup equal to 1.3 at zero inflation (so that the elasticity of demand $\varepsilon$, is 4.33). We also assume that $\eta=0.75$ (so that the average duration of price fixity is a year). Higher rates of inflation erode the markup, which approaches zero at an annual rate of inflation of about 25 percent per year. Since the markup acts like a tax on real activity (as discussed in Blanchard and Kiyotaki, 1987; Rotemberg and Woodford, 1991; and Goodfriend, 1995), declines in its level are associated with the substantial increases in output shown in the right panel of Figure 2.

Concretely, if the price adjustment gap were the only structural feature of price dynamics, then an increase in inflation from 5 percent to 10 percent would raise output permanently by about 7 percent.

Effects of forward-looking price setting. In a situation of sustained inflation, however, our model does not imply that price adjusting firms behave in the manner that underlies Figure 2. In particular, the ratio of newly set prices to marginal cost - the marginal markup-is given by

$$
\left[\frac{P_{t}^{*}}{\psi_{t}}\right]=\left[\left(\frac{\varepsilon}{\varepsilon-1}\right)\left(1-\frac{(1+\gamma) \eta}{\left(1+r^{s}\right)(1+\pi)^{1-\varepsilon}}\right)\right] \times\left[1-\frac{(1+\gamma) \eta}{\left(1+r^{s}\right)(1+\pi)^{-\varepsilon}}\right]^{-1} \text {. }
$$


This expression is a steady-state version of equation 16 in which $\gamma$ is the real growth rate of the economy, $r^{s}$ is the real interest rate appropriate for discounting the firm's cash flows (given by the real rate of interest on the stock market, about 6.5 percent), and

$$
\frac{\varepsilon}{\varepsilon-1}
$$

is the markup that would prevail in the absence of staggered price setting (that is, with $\eta=0$ ). The optimal pricing rule makes this ratio depend positively on the inflation rate. A higher expected rate of inflation leads firms to set a higher price when they are free to adjust, principally because they know that as long as their nominal price remains fixed, inflation will erode both their relative price and the real value of any markup established today. The former erosion means there is increasing substitution toward a product as long as its price is fixed. The latter erosion means that per-unit profits fall for as long as a price is fixed. Since firms must fill demand at posted prices, they attempt to counter these two effects by setting higher markups in the face of higher inflation rates.

\section{The Approximate Optimality of the Friedman Rule}

A striking feature of our setup is that the Friedman rule is approximately optimal under a wide range of assumptions about the magnitude of price adjustment $(\eta)$, the extent of the static markup

$$
\left(\mu=\frac{\varepsilon}{\varepsilon-1}\right),
$$

and the specification of the transactions technology. By approximate optimality, we mean the following. Since the transactions technology implies a satiation point for cash balances, at the Friedman rule, there must be a zero loss to holding a slightly smaller amount of real cash balances. Thus, if the markup can be reduced by slightly more inflation at the Friedman rule (as it can for the parameters that we study), then there will be an unambiguous welfare gain to increasing inflation from the Friedman rule. 9 Although this point can be established formally, one needs a microscopic inspection of the welfare trade-off to find it in the experiments reported below: The maximum welfare point occurs very close to the Friedman rule.

The benchmark case. To begin, the top panel of Figure 3 shows the relationship between welfare in the steady state and the rate of inflation for a benchmark case. In this benchmark case, we assume that

$$
\eta=0.75, \mu=\frac{\varepsilon}{\varepsilon-1}=1.3,
$$

and make other assumptions about the steady state of the model presented in Table 1. (These other parameter assumptions are conventional in the quantitative business cycle literature.) The reference point for our analysis is a situation of 5 percent inflation, indicated by ${ }^{\star}$ in Figure 3.

In models that abstract from variations in labor supply, a standard measure of welfare is the fraction of steady-state consumption that an individual would give up to avoid a distortion (as in Lucas, 1990). In our setting with variable labor supply, we use the measure of welfare depicted 


\section{Figure 3}

\section{Steady State Welfare}

A. Welfare Compared with Baseline of 5 Percent Inflation

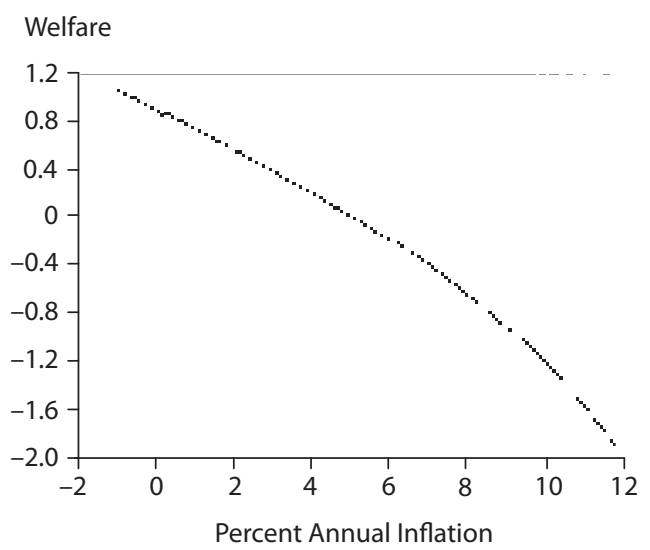

\section{B. The Welfare Measure}

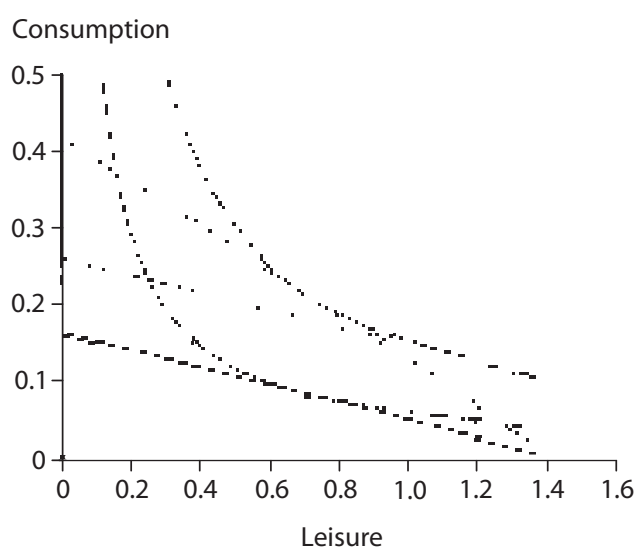

graphically in the lower panel of Figure 3-the amount of additional consumption expenditure that could be purchased by an individual at an initial relative price of consumption and leisure. 10 Although we measure the change in full income along the vertical axis of the right panel of Figure 3, valuing changes in leisure and consumption at a constant relative price, we express the welfare effect as a fraction of measured national income, so it is directly comparable to other measures of welfare losses expressed as a fraction of steady-state national income.

The salient features of Figure 3 are twofold. First, as the rate of inflation falls toward $\pi^{f}=-1$ percent from the reference level of $\pi=5$ percent there is a substantial increase in welfare. Fundamentally, this increase arises because there is a decrease in shopping time when the nominal interest rate falls and the associated cost of money holding falls. Recent work by Lucas (1993) has documented the magnitude of these welfare gains in economies simpler than those studied in this article, namely ones that abstract from variable labor supply, physical capital accumulation, and staggered price setting. He finds gains on the order of 1.5 percent of national product, a useful benchmark for our discussion.

In our setting, the magnitude of the welfare gain to pursuing the Friedman rule is 1.1 percent of national income. The gain to moving from 5 percent inflation to 0 percent inflation is about 0.8 percent of national income. Second, Figure 3 also shows that there are quantitatively important welfare losses from raising inflation from the benchmark level of 5 percent: An increase in the inflation rate from 5 percent to 12 percent lowers welfare by 2 percent.

Interpretation. In Figure 1, there was a gain from lowering inflation since the society economized on transactions time. In Figure 2, there was a gain from raising inflation-inflation eroded markups and lower markups stimulated economic activity. Given the magnitude of the real effects in Figures 1 and 2, one would suspect a strong case for high inflation. Yet, when these two forces are combined (as in Figure 3), there is a strong case for low inflation. 


\section{Figure 4}

\section{The Markup and Inflation}

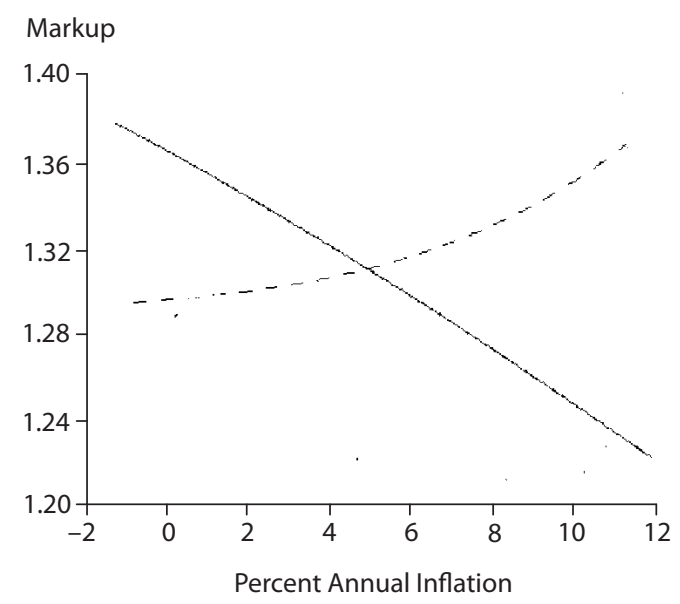

\section{Table 1}

Parameters

$\varepsilon \quad$ Own price demand elasticity 4.33

$\eta \quad$ Probability price does not change $\quad 0.75$

$\zeta \quad$ Multiplicative term in $h$ ( ) function 0.01156

$v$ Curvature of $h($ ) function $\quad 0.8004$

$\kappa \quad$ Shift term in $h($ ) function $\quad 0.0011$

$s_{n} \quad$ Labor share $2 / 3$

$\delta \quad$ Quarterly depreciation rate $\quad 0.025$

$\xi \quad$ Investment adj. cost parameter 2 $-\left((i / k)\left(\phi^{\prime \prime} / \phi^{\prime}\right)\right)^{(-1)}$

$\gamma \quad$ Quarterly real growth rate (3 percent annually) $\quad 0.0074$

$\pi \quad$ Quarterly inflation rate (5 percent annually) 0.0122

$\beta \quad$ Utility discount factor (quarterly) $\quad 0.9917$

Utility function: $u(c, l)=\ln (c)+2.47 \cdot \ln (I)$

The main reason for this striking finding is that the experiment displayed in Figure 2 leaves out the incentives firms have to change their price-setting behavior in a situation of sustained inflation. That is, in our model, a situation of positive steady-state inflation involves two offsetting displacements relative to price stability. The first is that inflation opens a price adjustment gap, lowering the average markup because

$$
\left[\frac{P_{t}}{P_{t}^{*}}\right]<1 .
$$

The second is that the marginal markup rises with inflation as firms seek to avoid an erosion of their relative price and markup. Figure 4 contrasts the overall effect of inflation on the steadystate markup (dashed line) to the partial effect from Figure 2 that takes into account only the price adjustment gap (solid line).

There are two distinct regimes. Over the range relevant for considering a decrease in inflation relative to the benchmark level of 5 percent, the average markup is relatively unaffected by inflation: The incentives that firms have to raise the marginal markup are just offset by the decline (via the price adjustment gap) in the average markup. $\frac{11}{}$ For this reason, the welfare analysis of inflation coincides with Friedman's analysis. Over the range relevant for considering increases in inflation relative to its benchmark level, significant increases occur in the average markup. This response stems from an even larger effect on the marginal markup, that in turn reflects sufficient demand response to the real price declines associated with inflation that firms choose to increase the marginal markup dramatically to avoid the prospect of satisfying unprofitable demand in the future.

Sensitivity analysis. We now present a brief sensitivity analysis. Six dimensions exist along which it seems natural to explore the robustness of the relationship between welfare and inflation depicted in Figure 4. 


\section{King and Wolman}

- How different is the size of the cost of inflation in our sticky price, monopolistically competitive setting from that in a flexible price, perfectly competitive setting?

- How would this cost be overestimated if one viewed price setters as myopic, in the same way we did in constructing Figure 1 and as was frequently done in traditional Keynesian macroeconometric models?

- How different would the costs of inflation be if the economy were much less competitive?

- How sensitive is the cost of inflation to higher values of $\eta$, that is, to more inertia in prices?

- How is the cost of inflation affected by eliminating the inflation distortion between consumption and leisure?

- How sensitive is the cost of inflation to our assumption that there is a satiation level of real cash balances?

The six panels of Figure 5 display the answers to these questions. In each panel, we use the dashed line to represent the results from the benchmark case and a solid line to represent those from the case under study.

Variations in competition, price rigidity, and forward-looking behavior. In conducting the first four alterations in the model, we assumed that the economies were each calibrated at a 5 percent inflation rate, so that the new and old lines all rotate through the 5 percent inflation point. In panel A the effect of moving to perfect competition and flexible prices is shown: There is minimal difference. In panel $\mathrm{B}$ we provide a case similar to that underlying Figure 2 in which price setters are assumed not to be forward-looking: It is the single case we have found of a setting in which there is a case for increased inflation (a very strong one). In panel $\mathrm{C}$ we see the effect of raising the static markup from 1.3 to 3 : The effect is to slightly increase the welfare benefit from reducing inflation. The analysis of Goodfriend (1995) can be used to explain this result. With less competition (higher $\mu$ ), the wage rate is a smaller fraction of labor's marginal product and output is correspondingly further below its efficient level. Thus, when labor flows out of transactions activity and into productive activity, there is a larger welfare gain. In panel D we see the effect of raising the expected duration of price setting from 4 quarters to 10 quarters, that is, the effects of an increase in $\eta$ from 0.75 to 0.8 . There is little effect on the benefits from lower inflation but a larger increase in costs of higher inflation. $\underline{12}$

Variations in the money demand specification. In panel $\mathrm{E}$ we show the effect of eliminating the implications that the money demand function has for the full price of consumption: We set the term

$$
w_{t+j} D h\left(\frac{m_{t+j}}{c_{t+j}}\right)\left(\frac{m_{t+j}}{c_{t+j}^{2}}\right),
$$

to zero in the expression (equation 5) for optimal consumption. We view this as the traditional neoclassical and monetarist procedure of ignoring the implications of the cost of money holding for the full price of consumption - it is used, for example, in most textbooks with strong neoclassical underpinnings, such as Bailey (1971), Barro (1990), and Abel and Bernanke (1992). However, this assumption is the polar opposite of that made in cash-in-advance models of money, where the transactions technology implicitly makes variations in the ratio of consumption to 


\section{Figure 5}

\section{Sensitivity Analysis}
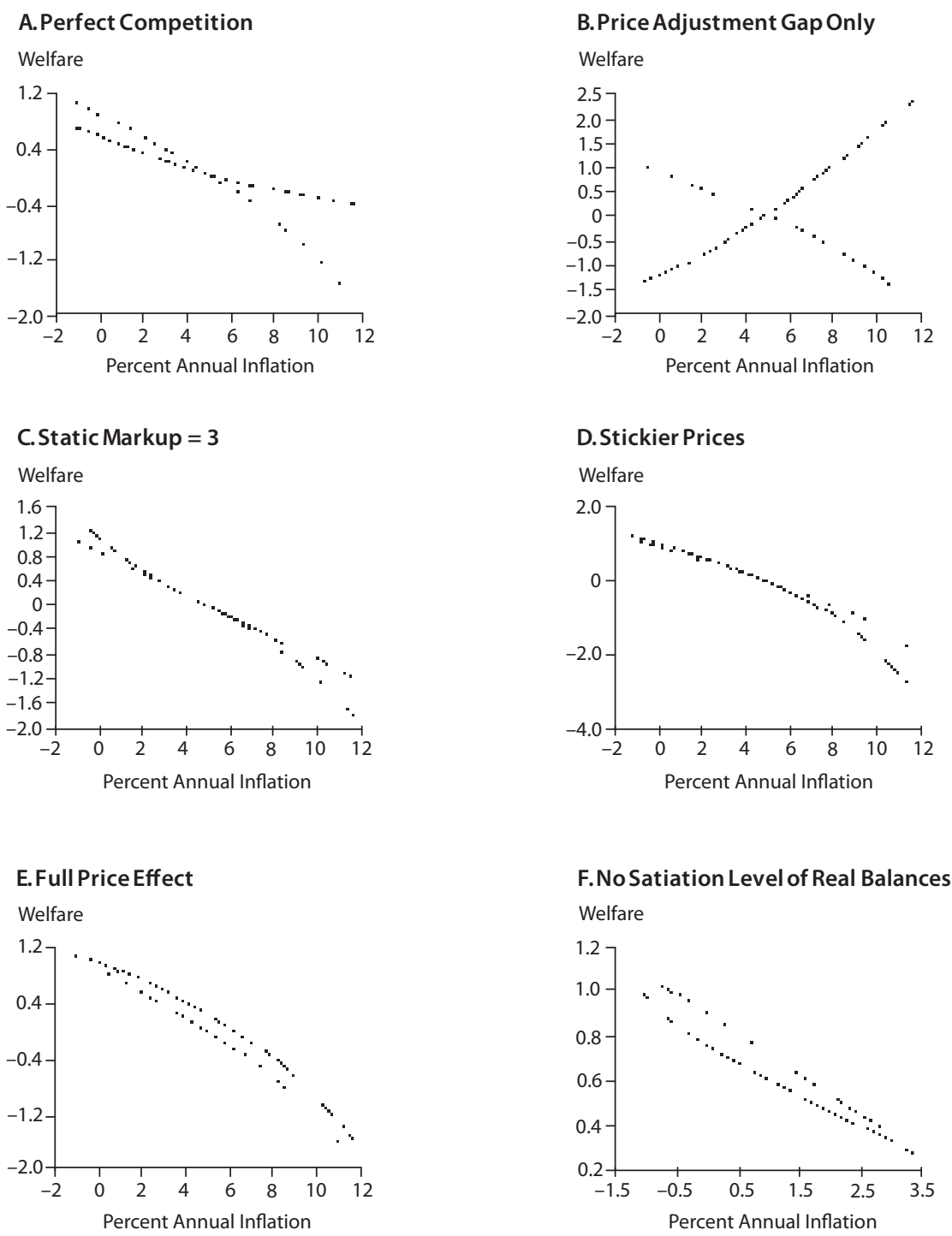

money infinitely expensive in terms of time. That is, in the cash-in-advance analysis of Cooley and Hansen (1992), there is only a full price effect of inflation, not a time reallocation effect associated with costly substitutions in transactions activities designed to avoid the inflation tax. Panel E shows small differences in our cost of inflation measure for small rates of inflation, but these become more pronounced as the inflation rate increases. Thus, the traditional neoclassi$\mathrm{cal}$ and monetarist procedure is a good approximation for small and moderate inflations, but it would likely not be for hyperinflations. In panel $\mathrm{F}$, we investigate the effect of ruling out satiation in real balances (imposing the restriction $\kappa=0$ when estimating the money demand function). 


\section{King and Wolman}

Lucas (1993) imposes such an assumption that has the effect of making the Friedman rule exactly rather than approximately optimal. $\underline{13}$ However, in other ways it has little effect on our welfare computations.

\section{INFLATION TARGETING AND BUSINESS CYCLES}

Having established that benefits to targeting a low rate of inflation exist in the long run, we turn next to evaluating how a policy of inflation targeting influences the dynamic response of our economy to various shocks. For this purpose, we use a perfect inflation targeting scheme in which the central bank is presumed to manipulate the money supply each period so as to achieve exactly the target rate of inflation (an annualized 5 percent rate of inflation in our experiments). Then we ask how real activity responds to productivity and money demand shocks that we take to be two major sources of disturbances. We model these as random walk shocks because we think these are largely permanent in nature.

The motivation for this part of the investigation is to see what gains or losses would arise if the central bank could target the inflation rate accurately. In particular, we are concerned with whether price-level targeting introduces major gaps relative to the real outcomes that would arise if there were perfect price flexibility. The bottom line is that it does not, according to both "eyeball" and formal welfare measures. In fact, compared with a policy of money supply targeting, inflation targeting succeeds in eliminating these gaps. To understand this result, it is necessary to understand how real activity responds to shocks under money supply targeting. Our analyses of productivity and money demand shocks thus begin with this case. We subsequently discuss how and why responses differ under inflation targeting.

\section{Productivity Shocks}

Figure 6 displays the impulse response functions to a permanent productivity shock of output, consumption, investment, hours, the average markup, the real wage, the real interest rate, and real balances, assuming that the money growth rate is held constant. $\frac{14}{}$ The dashed lines describe a flexible price economy $(\eta=0)$, and the solid lines describe a sticky price economy $(\eta=0.75)$. To explain the marked differences between the two sets of curves, it is helpful to decompose the average markup as in the section on estimating the welfare gains from lower inflation. We can use the decomposition (equation 17) at any date to write the average markup as,

$$
\underline{\mu}_{t}=\left[\frac{1-\eta}{1-\eta\left(P_{t-1} / P_{t}\right)^{(1-\varepsilon)}}\right]^{\frac{1}{1-\varepsilon}}\left[\frac{P_{t}^{*}}{\psi_{t}}\right],
$$

also recognizing that the price level evolves according to equation 15 to describe the price adjustment gap as a function of the current and past price level.

Productivity shock dynamics under a fixed money supply rule. Under a fixed money supply rule, we find the intuitive result that a permanent productivity shock will raise output (Figure 6, panel A) and lower the current price level from its trend when prices are flexible. Since capital and consumption grow slowly toward the new steady state, a situation of sustained defla- 


\section{Figure 6}

\section{Money Supply Targeting, Response to a Permanent Productivity Shock}

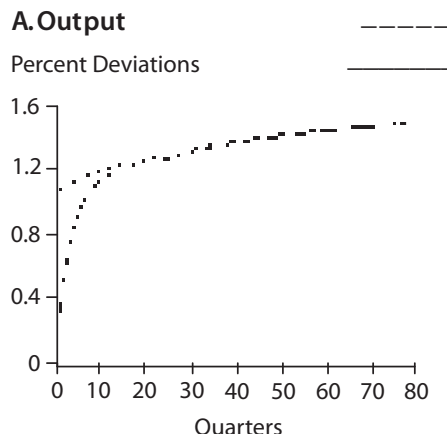

C.Consumption

Percent Deviations

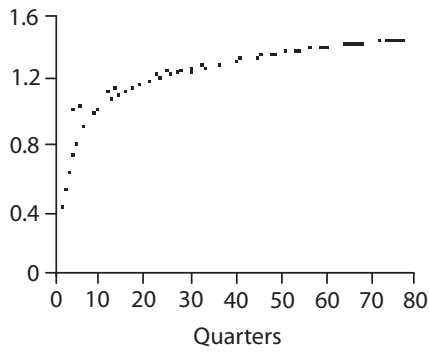

E.Markup

Percent Deviations

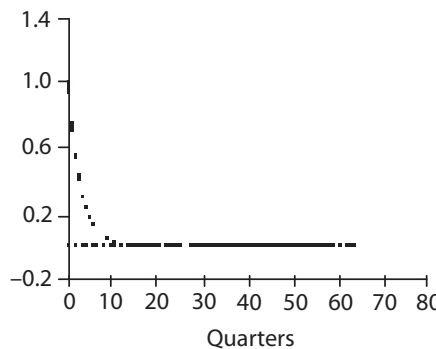

G. Real Interest Rate

Percent Deviations

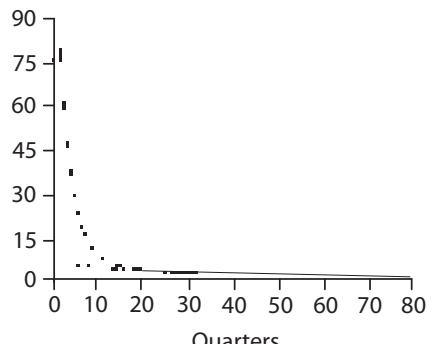

$\eta=0$

$\eta=0.75$

\section{B. Investment}

Percent Deviations

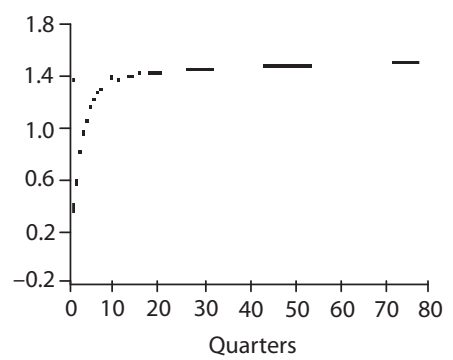

D. Labor Input

Percent Deviations

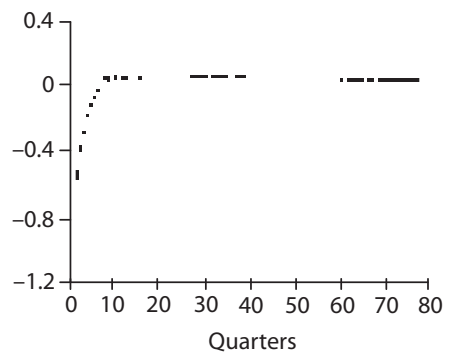

F. Real Wage

Percent Deviations

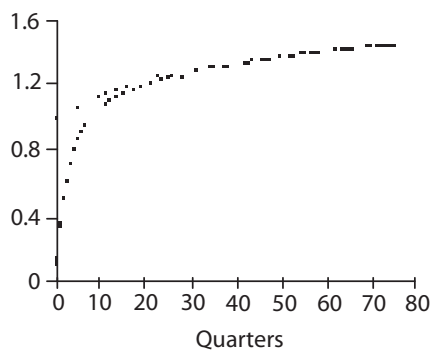

H. Real Balances

Percent Deviations

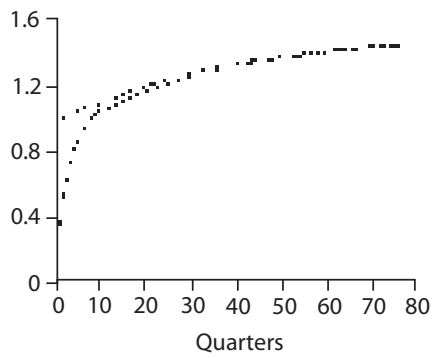




\section{King and Wolman}

tion is shown in Figure 6: This is to be interpreted as the price level rising at less than the benchmark 5 percent rate.

If prices are sticky, there is also pressure for deflation. Accordingly, the first term in the markup expression (equation 20) rises when the price level falls, increasing the markup: This is the flip side of the inflation erosion effect discussed in the section on the price adjustment gap and inflation. Since the productivity shock lowers marginal cost at date $t$ and in all future dates, there is a relatively small effect on the marginal markup component

$$
\left[\frac{P_{t}^{*}}{\psi_{t}}\right] .
$$

The average markup rises in response to the productivity shock. A rise in the markup (Figure 6, panel E) implies an increase in the wedge between the marginal product of labor and the real wage (Figure 6, panel F). Since the wedge will eventually return to its steady-state level, there is a strong substitution effect that causes labor input (Figure 6, panel D) to fall in the impact period.

The direction of the effect on labor contrasts with the case in which prices are flexible and markups never deviate from $\varepsilon /(\varepsilon-1)$. In this case, labor input rises as agents capitalize on the temporarily high real interest rate. Thus under a money supply target, a sticky price economy responds to shocks in a qualitatively different manner than a flexible price economy.

Productivity shock dynamics with a perfect inflation target. The results differ substantially when there is a policy of perfectly targeting the inflation rate. Figure 7 displays comparable impulse response functions in this case (the target inflation rate is 5 percent). A glance at Figure 7 reveals that, unlike the money growth target case, there is no qualitative difference between the responses under fixed and flexible prices. The average markup decomposition is again helpful in understanding this result. Because inflation targeting prevents shocks from affecting the price level, it eliminates the price adjustment gap channel-the first term in the decomposition-so that there is no tendency for the markup to rise (Figure 7, panel E). With the markup essentially unchanged, the real wage fully inherits the increase in productivity. Thus, a major component of the substitution effect acting to decrease labor supply disappears and, as in the flexible price model, hours rise in accord with the opposing substitution effect of a temporarily high real interest rate (Figure 7, panels F, D, and G). Thus, perfect inflation targeting effectively makes a stickyprice economy behave like a flexible price economy: The key is that inflation targeting introduces a monetary accommodation that avoids the necessity for the price level to fall in response to permanent productivity shocks. $\underline{15}$

\section{Money Demand Shocks}

Figure 8 displays the results of a permanent shock to the demand for money under fixed money supply and price level paths, with the latter being equivalent to the outcome under flexible prices just as it was in response to a technology shock. Our money demand shock corresponds to a change in the cash balance efficiency condition such that there is a 1 percent higher demand for real balances at given levels of consumption, the real wage rate and the nominal interest rate. An important difference is evident between the two sets of results shown in Figure 8: An increase 


\section{Figure 7}

\section{Inflation Targeting, Response to a Permanent Productivity Shock}
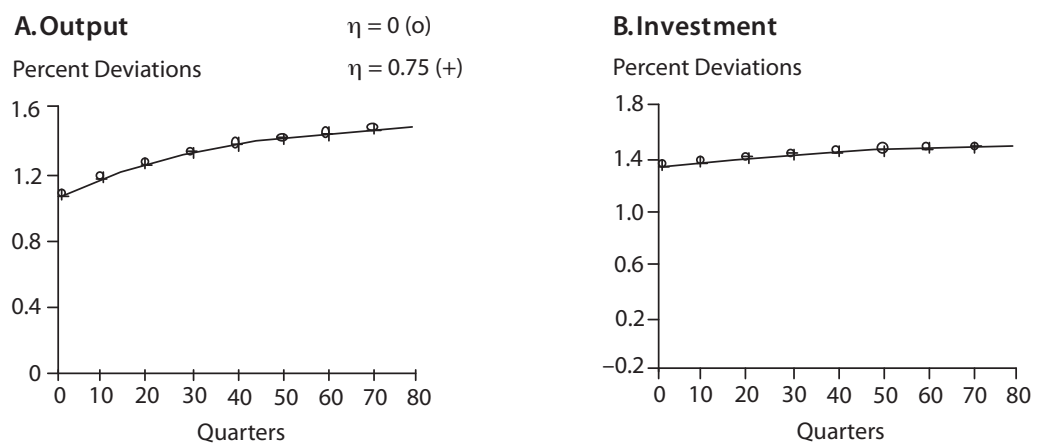

\section{C.Consumption}

D.Labor Input

Percent Deviations

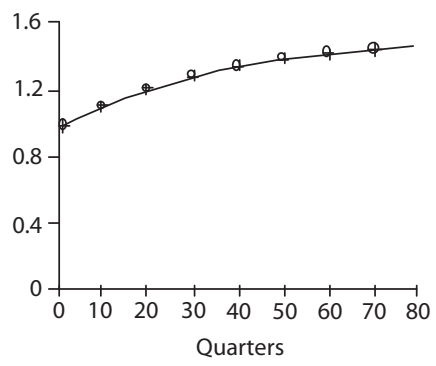

Percent Deviations

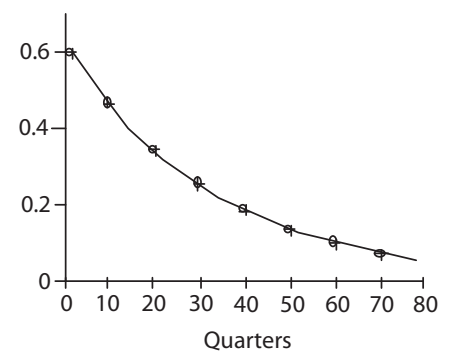

\section{E. Markup}

F. Real Wage

Percent Deviations

Percent Deviations
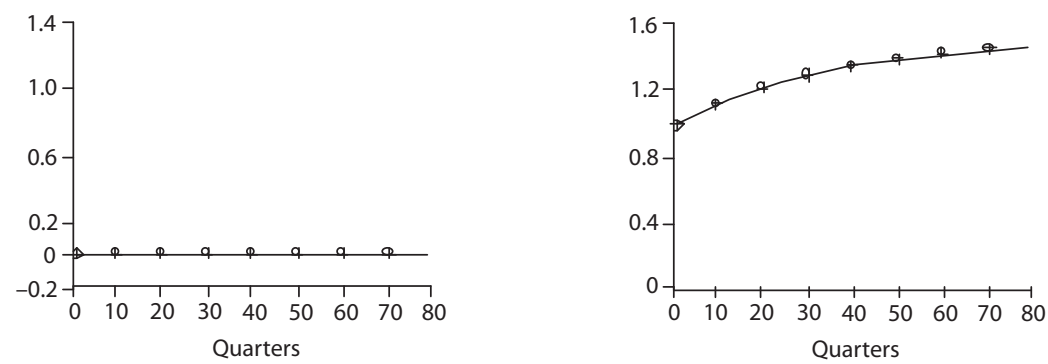

\section{G. Real Interest Rate}

Percent Deviations

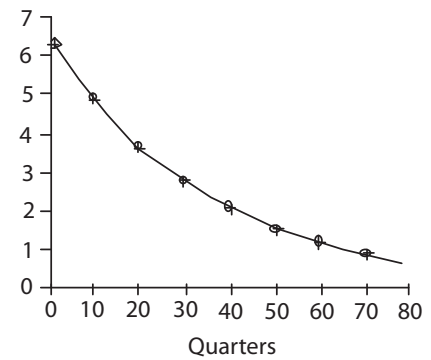

H. Real Balances

Percent Deviations

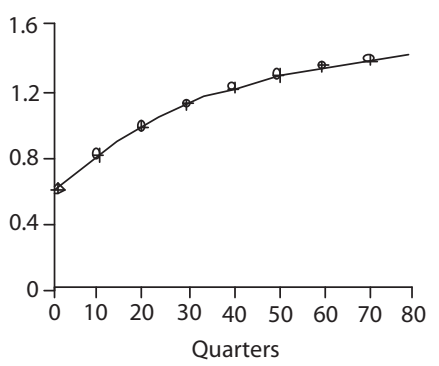




\section{Figure 8}

\section{Response to a Permanent Money Demand Shock}
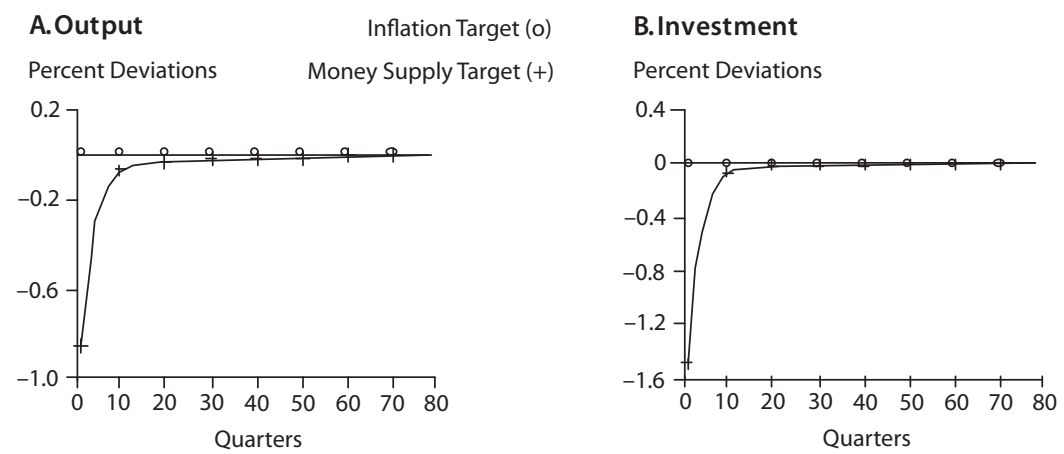

C.Consumption

D. Labor Input

Percent Deviations

Percent Deviations
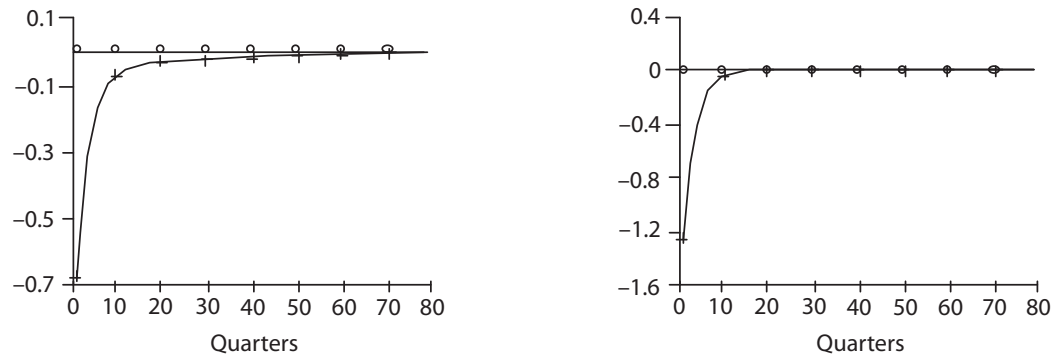

\section{E. Markup}

Percent Deviations

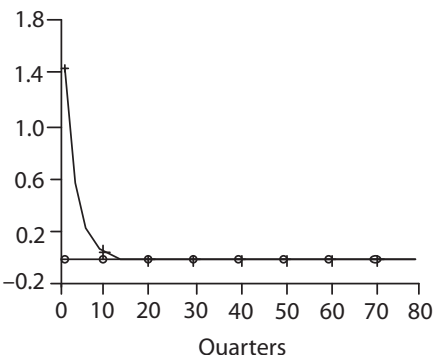

\section{F. Real Wage}

Percent Deviations

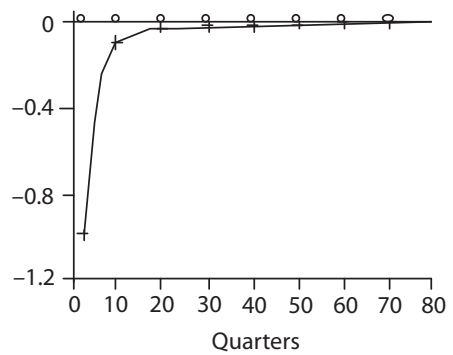

\section{G. Real Interest Rate}

\section{H. Real Balances}

Percent Deviations

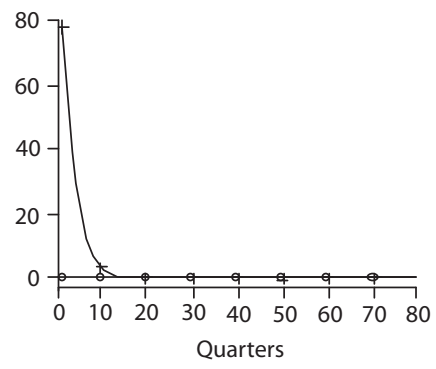

Percent Deviations

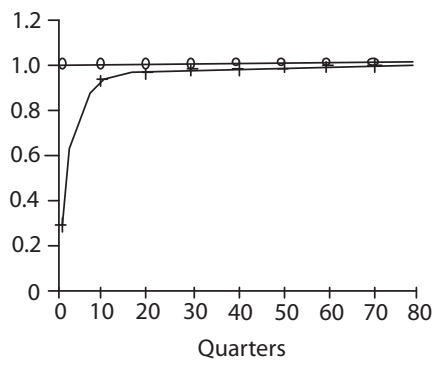


in money demand produces a decline in output if there is a fixed path of money, whereas it has no effect on output if policy is geared toward a stabilizing the price level.

\section{IMPLEMENTATION ISSUES}

We next discuss two sets of issues that would be a necessary part of implementing a policy rule like that discussed above. First, we ask whether it is possible to use the nominal interest rate as an instrument to implement a policy of controlling the price level in our model economy. Second, we investigate the consequences of immediately transiting to a lower inflation rate.

\section{Implementation with an Interest Rate Instrument}

Many central banks employ a short-term interest rate as the instrument by which monetary policy is implemented. To consider how our economy might respond to such an operating policy, we posit a monetary policy rule of the form:

$$
R_{t}=f \cdot\left[\log \left(P_{t}\right)-\log \left(\underline{P}_{t}\right)\right], \log \left(\underline{P}_{t}\right)=\log \left(\underline{P}_{t-t}\right)+\underline{\pi} .
$$

The first of these specifications indicates that the monetary authority raises the short-term nominal interest rate in response to increases in the general price level $\left(P_{t}\right)$ relative to its trend path $\left(\underline{P}_{t}\right)$, since we assume that the parameter $f$ is positive. The second of these specifications is our earlier requirement that the price level grow at a fixed target rate of inflation. $\frac{16}{}$ In Figure 9 , we reconsider the response of the macroeconomy to an increase in productivity under this rule, distinguishing between a strong and weak pattern of response. ${ }^{17}$

If the central bank follows a rule that requires it to respond strongly to deviations of the price level from its target path, then it actually must respond very little, and the economy's behavior closely resembles that under a perfect inflation target (these outcomes are the "o" path in Figure 9). To understand this rule, it is important to recall a very small (maximum seven basis points) response of the real interest rate under perfect price level targeting. Accordingly, by keeping the nominal rate essentially constant, the central bank can accommodate the productivity shock and keep the price level close to its target path. In this case, the post-Lucas-critique structure of the model is important. The interest rate policy keeps the price level close to the target because agents understand that deviations from the target would trigger large interest rate variations. This credible threat implies that such interest rate variations need never occur.

However, if the central bank responds only weakly to departures from the target path, then an overshooting of components of real activity may occur in response to a productivity shock. Essentially, in this setting, the central bank allows a gap between the actual and target price level to emerge as a result of the productivity shock-given that the real interest rate would rise under perfect inflation targeting, the policy rule makes the price level (not shown) rise initially in response to the shock, lowering the markup and raising real quantities. Later the price level falls back to the target path, but this is of little consequence for real activity since it is largely forecasted by private agents. 


\section{King and Wolman}

\section{Figure 9}

Interest Rate Rule, Feedback from Price Level, Response to a Permanent Productivity Shock
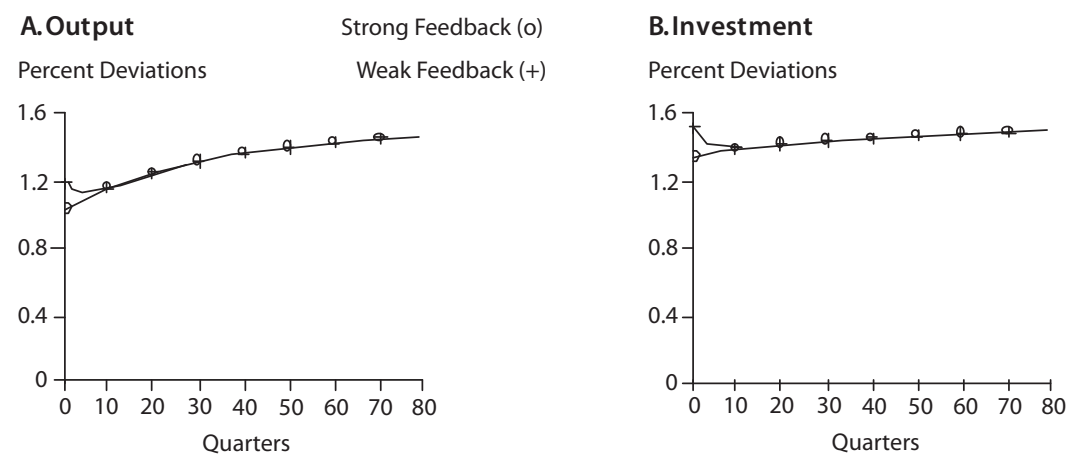

\section{C.Consumption}

\section{D.Labor Input}

Percent Deviations

Percent Deviations
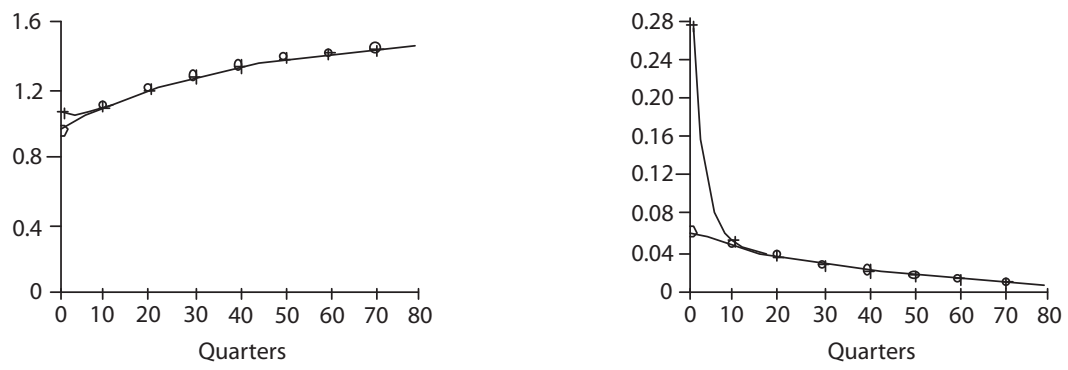

\section{E. Markup}

Percent Deviations

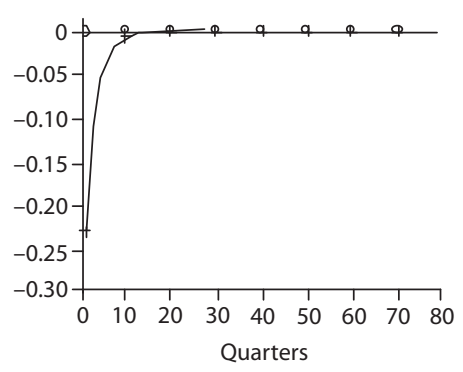

F. Real Wage

Percent Deviations

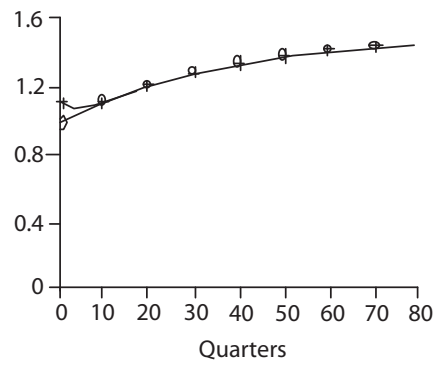

\section{G. Real Interest Rate}

\section{H. Real Balances}

Percent Deviations
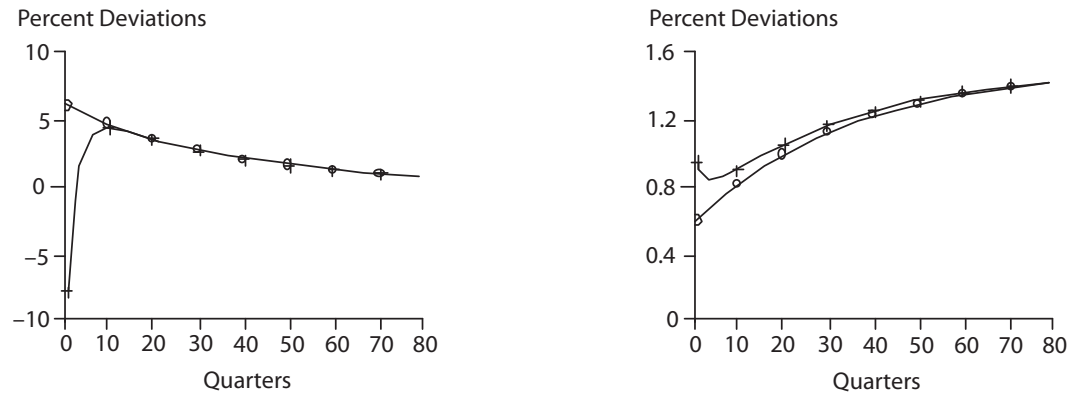


\section{Figure 10}

\section{Permanent Disinflation}

A. Output

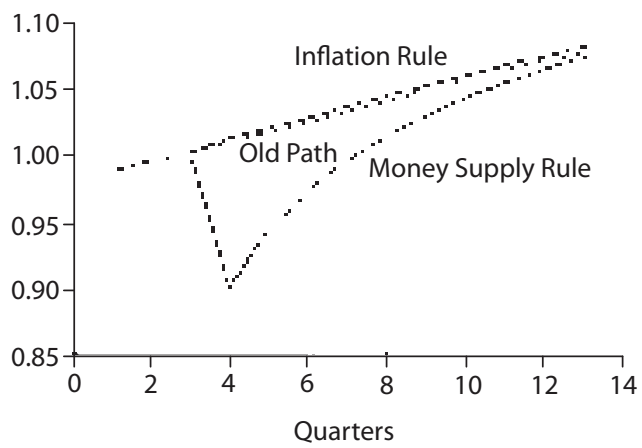

C. Price Level

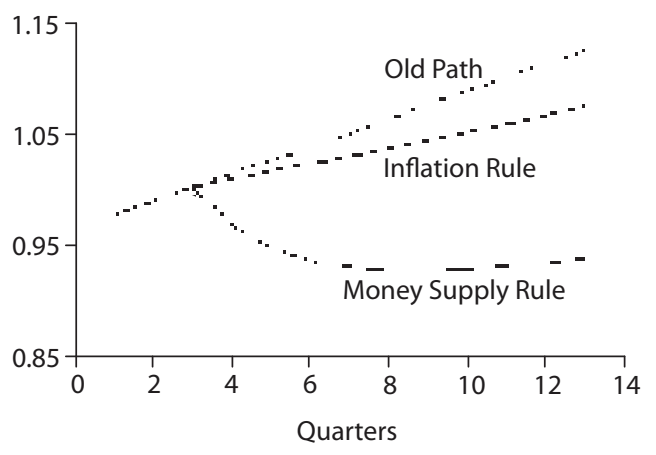

B. Money Stock

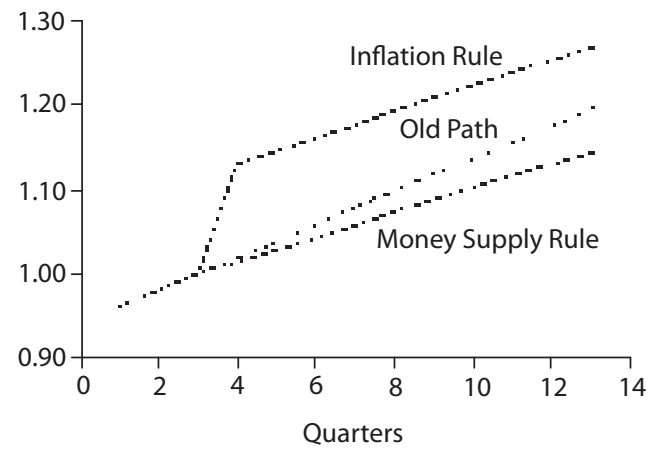

Thus, when policy is implemented by means of an interest rate instrument, the economy's response to shocks is highly sensitive to the specific form of the policy rule. Since rules involving interest rates are inherently dynamic, understanding the implications of different policy settings requires an understanding of the patterns of expectations generated by the rules in response to a shock.

\section{Timing of Implementation}

If a central bank seeks to lower the inflation rate in the long run through an inflation targeting rule, are there important costs of immediate implementation? In other words, should a gradual approach to disinflation be preferred to an immediate one within our model economy? Advocates of gradualism sometimes argue that a recession will result from abrupt disinflation.

Figure 10 shows the results of an experiment of lowering the annual rate of inflation from 5 percent to 3 percent under two alternative schemes. Under an inflation rule, there is no transitional output loss from disinflation - there is simply a small gain in real activity as labor flows out of transactions activity and into the production of final goods. This outcome results from 


\section{King and Wolman}

the structure of price dynamics in the Calvo model, as previously discussed by Buiter and Miller (1985) and Ball (1994). Inflation can readily jump from one of the steady states (considered above) to another-there are no important inertial forces governing the inflation rate, as opposed to the price level, within our model economy.

However, as indicated by the paths marked money supply rule, there are important consequences of a change in the money growth rate-as distinguished from a change in the inflation rate-within the model. Since a lower long-run inflation rate will stimulate the demand for money, the path of the price level must fall if there is a decline in the long-run rate of monetary growth. The process of transition from a high price level path to a lower one can be associated with substantial declines in economic activity, as Figure 10 makes clear.

\section{SUMMARY AND CONCLUSIONS}

We have explored the costs and benefits of inflation targeting in a modern macroeconomic model of the link between nominal and real variables. From the St. Louis model of 1972, we took an emphasis on monetarist specification of money demand, as well as of the importance of expectations in price setting. From recent developments in macroeconomics, we took the money demand function as arising from a specific transactions technology, rational expectations, and explicit dynamic modeling of consumption, labor supply, investment, and price setting. More specifically, we followed work by Calvo (1983), Rotemberg (1987), and Yun (1996) in modeling an economy that combines short-run price stickiness with rational decisions of firms. We used our setup to evaluate the potential costs and benefits of a policy of targeting the inflation rate.

Our conclusions are in line with those of earlier monetarists-Irving Fisher, Milton Friedman, and the builders of the St. Louis model. We found that the target rate of inflation should be set at a low level. At current U.S. levels of inflation, the benefits from low inflation (that is, the economy reduces its time spent making transactions) are first order and the frictions associated with imperfect competition and gradual price adjustment are second order. We also found this perfect inflation targeting policy produces responses to productivity and money demand shocks that are in line with those which would arise in a flexible-price economy. Finally, we briefly explored two issues associated with the implementation of an inflation targeting policy, showing that it can be implemented with an interest rate instrument and that there can be an immediate disinflation without adverse consequences for real economic activity.

This study of an inflation-targeting policy leaves open many interesting questions. First, our analysis of price dynamics following Calvo was relatively rudimentary in terms of the stochastic structure of price adjustment. A more complete analysis would permit a richer time pattern of anticipated adjustment and also permit that time pattern to respond to the state of the economy, specifically to the average rate of inflation. Second, our analysis leaves open the important question of how a regime of imperfectly credible inflation targets would operate. Third, it would be useful to pose the counterfactual question, What would have been the welfare gains if the United States had been on an inflation-targeting regime during the postwar period? These topics are the subject of our continuing research into inflation targets within a St. Louis model of the 21st century. 


\section{NOTES}

1 Andersen and Carlson (1972) discuss the central role of expectations in the St. Louis model. We further discuss their modeling of expectations below.

2 Our timing convention for money demand embodies a view of the average cash balance holdings as a durable good (as in Friedman, 1969) and is best exposited as follows. Suppose that the evolution of bonds is

$$
\frac{1}{1+R_{t}} B_{t+1}+M_{t}+P_{t} c_{t}=Y_{t}+B_{t}+M_{t-1}
$$

where $Y_{t}$ is some measure of nominal income and $B_{t}$ is the quantity of bonds maturing at $t$. Accordingly, the date $t$ cost of holding a unit of money from $t$ to $t+1\left(M_{t}\right)$ is the discounted value of the interest forgone,

$$
\frac{R_{t}}{1+R_{t}}
$$

as in the text.

$\underline{3}$ In the interest of making the model setup as simple as possible notationally, we are being a little cavalier about the role of uncertainty. For certain cash flows, our discount factor is linked to one period interest rates by

$$
\Delta_{t, j}=\left[\left(1+R_{t}\right) \ldots\left(1+R_{t+j-1}\right)\right]^{-1},
$$

where $R_{t}$ is the nominal interest rate from $t$ to $t-1$.

4 The introduction of investment adjustment costs is not necessary to any of the main conclusions that follow from in our analysis below. However, as aconsequence of the evidence summarized in Chirinko (1993), there is a good reason for incorporating this structural aspect into a modern macroeconomic model.

5 Nevertheless, the Calvo setup is a natural starting point for our analysis: In Dotsey, King, and Wolman (1996), we argue that a somewhat more general time-dependent specification is formally a first-order approximation to a richer statedependent price-adjustment model.

6 This specification requires that we view the consumption and investment goods as the same constant elasticity of substitution "aggregator" of differentiated products. Blanchard and Kiyotaki (1987) derive such individual product demand functions for a model with just a consumption good.

$\underline{7}$ The money stock is M1. The interst rate is a quarterly yield on commercial paper. We form $\mathrm{m} / \mathrm{c}$ as the ratio of nominal money to an annual nominal consumption expenditure series (including durables). We then divide by population and express the figure in terms of quarterly time units by multiplying by 4 . Similarly, we divide nominal quarterly per capita consumption by a nominal wage rate, measured as average hourly earnings of production workers in manufacturing, in current dollars. The average value of the resulting $c / w$ series indicates that a representative worker requres 249 hours of work per quarter to purchase consumption or about 20 hours per week. In terms of interpreting Figure 1, however, the reader should know that we have rescaled $c / w$ by dividing by average quarterly hours worked. Additional details on the data (and the data themselves) are provided in a replication diskette that you can request from the authors.

8 Several recent papers make this point in differing settings. Benabou (1992) suggests that higher inflation may raise the elasticity of demand in a search model, thus lowering the markup. In a model that shares the core neoclassical structure of this article, but uses a differing pattern of price dynamics, Goodfriend (1995) also derives a link between the markup and inflation.

9 Michael Woodford and Preston McAfee each forcefully pointed out this conclusion to us during presentations of this paper.

10 This follows Baxter's (1995) analysis of tax distortions in a variable labor supply setting.

11 For the parameter values we use, the markup is decreasing with inflation in a neighborhood of the Friedman rule. This leads to the approximate optimality result discussed in the introduction to this section.

12 The $\eta=0.8$ value is an upper bound for our analysis, given our demand parameter ( $\mu$ or $\varepsilon$ ). With higher values of $\eta$, there is a sufficiently large cost of getting stuck with a fixed price that it is optimal not to open a firm. This example indicates an unfortunate tension between matching short-run price dynamics and longer run inflation responses in the Calvo model, one reason for the generalizations considered in Dotsey, King, and Wolman (1996). 


\section{King and Wolman}

13 That is, the slope of the solid line is infinitely negative at $\pi^{f}$ in Lucas's analysis rather than slightly positive as in our analysis.

14 The impulse response functions in Figures 6 to 10 were generated by linearizing the model around its deterministic steady-state growth path, using the singular linear system methods detailed in King and Watson (1995a and b).

15 A formal welfare comparison supports the conclusion that sticky price and flexible price economies are not very different under perfect inflation targeting. To produce this measure in an earlier draft of the article, we determined the welfare effect of a shock using the dynamic equivalent of the measure described in the section on optimal inflation policy in the long run and illustrated in the right panel of Figure 2. Linear approximation methods were used to compute these welfare changes that are related to the measure of the Hicksian wealth effects of shocks produced in King (1993).

16 McCallum (1981) makes it clear that such interest rate policies are a feasible mode of central bank behavior so long as policy is conducted so as to produce a nominal anchor for the price level. Fang, Kerr, and King (1995) show that an interest rate policy will result in unique outcomes so long as $f>0$.

17 We chose these values $f=500$ (strong policy) and $f=0.1$ (weak policy) to produce clear graphics that illustrate the nature of the policy rule.

\section{REFERENCES}

Abel, Andrew B., and Ben S. Bernanke. Macroeconomics. Addison-Wesley, 1992.

Andersen, Leonall C., and Keith M. Carlson. "An Econometric Analysis of the Relation of Monetary Variables to the Behavior of Prices and Unemployment," in The Econometrics of Price Determination, Otto Eckstein, ed. Board of Governors of the Federal Reserve System, 1972, pp. 166-83.

Andersen, Leonall C. and Jerry Jordan. "Monetary and Fiscal Actions: A Test of their Relative Importance in Economic Stabilization," Federal Reserve Bank of St. Louis Review (October 1968), pp. 29-44.

Bailey, Martin J. National Income and the Price Level: A Study in Macroeconomic Theory, 2nd ed. McGraw Hill, 1971.

Ball, Laurence. "Credible Disinflation with Staggered Price Setting," The American Economic Review (Vol. 84, 1994), pp. 282-89.

Barro, Robert J. Macroeconomics, 3rd ed. Wiley, 1990.

Benabou, Roland. "Inflation and Markups: Theories and Evidence from the Retail Trade Sector," European Economic Review (Vol. 36, 1992), pp. 566-74.

Blanchard, O. J., and N. Kiyotaki. "Monopolistic Competition and the Effects of Aggregate Demand," The American Economic Review (September 1987), pp. 647-66.

Bodkin, Ronald G. "Wage and Price Formation in Selected Canadian Econometric Models," in The Econometrics of Price Determination, Otto Eckstein, ed. Board of Governors of the Federal Reserve System, 1972, pp. 369-85.

Buiter, Willem H., and Marcus H. Miller. "Costs and Benefits of an Antilnflationary Policy: Questions and Issues," in Inflation and Unemployment: Theory, Experience, and Policymaking, Victor E. Argy and John W. Neville, eds. London: Allen and Unwin, 1985.

Calvo, G. A. "Staggered Prices in a Utility-Maximizing Framework," Journal of Monetary Economics (September 1983), pp. 383-98.

Chirinko, Robert S. "Business Fixed Investment Spending: A Critical Survey of Modelling Strategies, Empirical Results, and Policy Implications," Journal of Economic Literature (Vol. 31, 1993), pp. 1,875-911.

Cooley, Thomas F., and Gary D. Hansen. "Tax Distortions in a Neoclassical Monetary Economy," Journal of Economic Theory (December 1992), pp. 290-316.

de Menil, George, and Jared J. Enzler. "Prices and Wages in the FRMIT-Penn Econometric Model," in The Econometrics of Price Determination, Otto Eckstein, ed. Board of Governors of the Federal Reserve System, 1972, pp. 277-308.

Dotsey, Michael; Robert G. King; and Alexander L. Wolman. "State Dependent Pricing and the Dynamics of Business Cycles." Manuscript, University of Virginia and Federal Reserve Bank of Richmond, 1996. 
Eckstein, Otto, ed. The Econometrics of Price Determination, Board of Governors of the Federal Reserve System, 1972.

Eckstein, Otto and Gary Fromm. "The Price Equation," The American Economic Review (Vol. 58, 1968), pp. 1,159-83.

Eckstein, Otto and David Wyss. "Industry Price Equations," in The Econometrics of Price Determination, Otto Eckstein, ed. Board of Governors of the Federal Reserve System, 1972, pp. 133-65.

Fang, Justin; William Kerr; and Robert G. King. "Limits on Interest Rate Rules in the IS Model." Manuscript, University of Virginia, 1995.

Friedman, Milton. The Optimum Quantity of Money, and Other Essays. Aldine Publishing Company, 1969.

Friedman, Milton and Anna J. Schwartz. A Monetary History of the United States 1867-1960. Princeton University Press, $1963 a$.

Friedman, Milton and Anna J. Schwartz. "Money and Business Cycles," Review of Economics and Statistics (February 1963b), pp. 32-78.

Goodfriend, Marvin S. "A Framework for the Analysis of Moderate Inflations." Manuscript, Federal Reserve Bank of Richmond, 1995.

Gordon, Robert J. "Discussion of Papers in Session II," in The Econometrics of Price Determination, Otto Eckstein, ed. Board of Governors of the Federal Reserve System, 1972, pp. 202-12.

Hayashi, Fumio J. “Tobin's Marginal q and Average q: A Neoclassical Interpretation," Econometrica (January 1982), pp. 213-24.

Ibbotson, Roger, and Rex Sinquefeld. Stocks, Bonds, Bills and Inflation: The Past and the Future. The Financial Analysts' Research Foundation, 1982.

King, Robert G. "Value and Capital in the Equilibrium Business Cycle Program," in Value and Capital: Fifty Years Later, L. McKenzie and S. Zamagni, eds. London: MacMillan (1993), pp. 279-309.

King, Robert G. and Mark W. Watson. "The Solution of Singular Linear Difference Models Under Rational Expectations." Manuscript, University of Virginia, 1995a.

King, Robert G. and Mark W. Watson. "System Reduction and Solution Algorithms for Singular Linear Difference Systems Under Rational Expectations." Manuscript, University of Virginia, 1995b.

Lucas, Robert E., Jr. "Econometric Policy Evaluation: A Critique," Carnegie-Rochester Conference Series on Public Policy (Vol. 1, no. 2 1976), pp. 19-46.

Lucas, Robert E., Jr. "On the Welfare Cost of Inflation." Manuscript, for the Hitotsubashi International Symposium of Financial Markets and the Changing World, 1993.

Lucas, Robert E., Jr. "Supply Side Economics: An Analytical Review," Oxford Economic Papers (April 1990), pp. $293-316$.

McCallum, Bennett T. "Price Level Determinacy with an Interest Rate Rule and Rational Expectations," Journal of Monetary Economics (Vol. 8, 1981), pp. 319-29.

McCallum, Bennett T. and Marvin S. Goodfriend. "Theoretical Studies of the Demand for Money," in The New Palgrave: A Dictionary of Economics; John Eatwell, Murray Milgate, and Peter Newman, eds. Stockton Press, 1987, pp. 775-81.

Okun, Arthur M. "Potential GNP: Its Measurement and Significance," Proceedings of the Business and Economic Statistics Section of the American Statistical Association, 1962, pp. 98-104.

Rotemberg, Julio J. “The New Keynesian Microfoundations," NBER Macroeconomics Annual. MIT Press, 1987, pp. 69-104.

Tobin, James. "The Wage-Price Mechanism: Overview of the Conference," in The Econometrics of Price Determination, Otto Eckstein, ed. Board of Governors of the Federal Reserve System, 1972, pp. 5-15.

Tobin, James. "Inflation and Unemployment," The American Economic Review (March 1972b), pp. 1-18.

Wolman, Alexander L. "Three Essays on Monetary Economics." Unpublished dissertation, University of Virginia, 1996.

Yun, Tack. "Nominal Price Rigidity, Money Supply Endogeneity, and Business Cycles," Journal of Monetary Economics (Vol. 37,1996), pp. 345-370. 
